\section{REFERENCES:}

1. Makauchi M, Mori T, Gunven P, et al. Safety of hemihepatic vascular occlusion during resection of the liver. Surg Gynecol Obstet 1989; 130:824-831.

2. Wobbes T, Bemelmans BLH, Kuypers JHC, et al. Risk of postoperative septic complications after abdominal surgery treatment in relation to preoperative blood transfusion. Surg Gynecol Obstet 1990; 171:
3. Belghiti J, Noun R, Malafosse R, et al. Continuous versus intermittent portal triad clamping for liver resection. A controlled study. Ann Surg 1999; 229:369 -375 .

4. J.R. Hiatt J.Gabbay,R W. Busuttil. Surgical Anatomy of the Hepatic Arteries in 1000 Cases. Ann Surg.1994 Vol. 220, No. $1,50-52$

5. Belghiti J, Noun R, Zante E, Ballet
T, Sauvanet A. Portal triad clamping or hepatic vascular exclusion for major liver resection. A controlled study. Ann Surg. 1996 Aug; 224(2):155-61

6. PE Clavien, S Yadav, d. Syndram, R. Bently. Protective Effects of Ischemic Preconditioning for Liver Resection Performed Under Inflow Occlusion in Humans. Ann Surg Vol. 232, No. 2, 155162

\author{
Corresponding author: \\ Ludmil Marinov Veltchev, MD PhD \\ Mobile: +359876259685 \\ E-mail: drlmarinov@yahoo.com
}

\title{
Journal of IMAB - Annual Proceeding (Scientific Papers) 2009, book 1
}

\section{OBESITY SURGERY: INDICATIONS, TECHNIQUES, WEIGHTLOSS AND POSSIBLE COMPLICATIONS - Review article}

\author{
Ludmil M. Veltchev \\ Fellow, Master's Program in Hepatobiliary Pancreatic Surgery, Henri Bismuth \\ Hepatobiliary Institute, 12-14, avenue Paul Vaillant-Couturier, 94804 Villejuif \\ Cedex
}

\section{SUMMARY}

In long-term perspective, the conservative treatment of obesity is always doomed to failure and only the surgical method allows reducing obesity. At this stage, the surgery of choice remains the gastric bypass, which is reduces on average $60-70 \%$ of the overweight and which is effective in $80 \%$ of the operated patients. Preoperative preparation, surgical interventions and postoperative monitoring of the patients are crucial to its effectiveness.

Key words: obesity, surgical techniques, complications

\section{INTRODUCTION}

The significant percentage increase of the population with overweight and the ineffectiveness of the medication treatment (diet, drugs) allow bariatric surgery to take an important place in the treatment $(\mathbf{1}, \mathbf{2})$. At this point this type of treatment is the only one leading to a lasting effect. Basically, two mechanisms allow the unification of all known methods into three categories:

- restrictive operations (gastric band and vertical gastroplastica)

- low absorbing operations (jejuno-ileal bypass, biliopancreatic derivation)

- mixed operations (gastric bypass)

\section{Description of techniques:}

a) Roux-en-Y Gastric Bypass (RYGB) works by restricting food intake and by decreasing the absorption of food. Food intake is limited by a small pouch that is similar in size to the adjustable gastric band $(3,4)$. In addition, absorption of food in the digestive tract is reduced by excluding most of the stomach, duodenum, and upper intestine from contact with food by routing food directly from the pouch into the small intestine. (fig. 1.)

b) Vertical Sleeve Gastrectomy (VSG) historically had 
been performed only as the first stage of BPD-DS (see above) in patients who may be at high risk for complications from more extensive types of surgery. These patients' high risk levels are due to body weight or medical conditions. However, more recent information indicates that some patients who undergo a VSG can actually lose significant weight with VSG alone and avoid a second procedure. It is not yet known how many patients who undergo VSG alone will need a second stage procedure. A VSG operation restricts food intake and does not lead to decreased absorption of food. However, most of the stomach is removed, which may decrease production of a hormone called ghrelin. A decreased amount of ghrelin may reduce hunger more than other purely restrictive operations, such as gastric band. (fig. 2.)

c) Biliopancreatic Bypass (BPD) et Biliopancreatic Bypass with duodenal switch (BPD-DS) Scopinaro $(5,6)$, usually referred to as a "duodenal switch," is a complex bariatric operation that principally includes 1) removing a large portion of the stomach to promote smaller meal sizes, 2) re-routing of food away from much of the small intestine to partially prevent absorption of food, and 3) re-routing of bile and other digestive juices which impair digestion. By

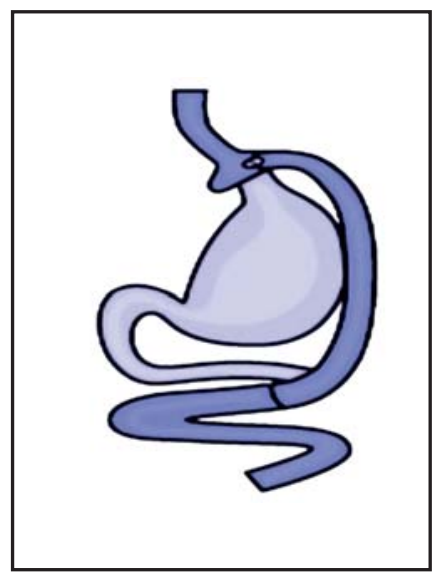

Fig. 1. Roux-en-Y Gastric Bypass

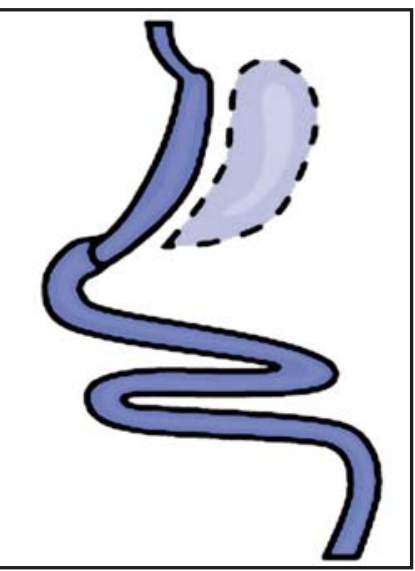

Fig. 2. Vertical Sleeve Gastrectomy

\section{INDICATION}

Regardless of the anesthesiology progress, surgery on patients with overweight always represents a risk. According to the formulated criteria, surgery is indicated in patients who have an index of total weight more or equal to $40 \mathrm{~kg} / \mathrm{mI}$, as well as in those patients with more than $35 \mathrm{~kg}$ / $\mathrm{mI}$ and one or more concomitant diseases caused by the obesity syndrome or taking a turn for the worse because of it. The obesity must date back to 5 years. There must be no effect of the conservative treatment. And no contraindications must be present, such as narcotic dependence, psychiatric disorders, chronic infections, liver

removing a large portion of the stomach, a more tubular "gastric sleeve" (also known as a vertical sleeve gastrectomy or VSG) is created. The smaller stomach sleeve remains connected to a very short segment of the duodenum, which is then directly connected to a lower part of the small intestine. This operation leaves a small portion of the duodenum available for food and the absorption of some vitamins and minerals. However, food that is eaten by the patient bypasses the majority of the duodenum. The distance between the stomach and colon is made much shorter after this operation, thus promoting malabsorption. BPD-DS produces significant weight loss. However, there is greater risk of long-term complications because of decreased absorption of food, vitamins, and minerals. (fig. 3.)

d) Adjustable Gastric Band (AGB) works primarily by decreasing food intake. It was developed by Morina at the end the $80 \mathrm{~s}$. Food intake is limited by placing a small bracelet-like band around the top of the stomach to produce a small pouch about the size of a thumb. The outlet size is controlled by a circular balloon inside the band that can be inflated or deflated with saline solution to meet the needs of the patient. (fig. 4.)

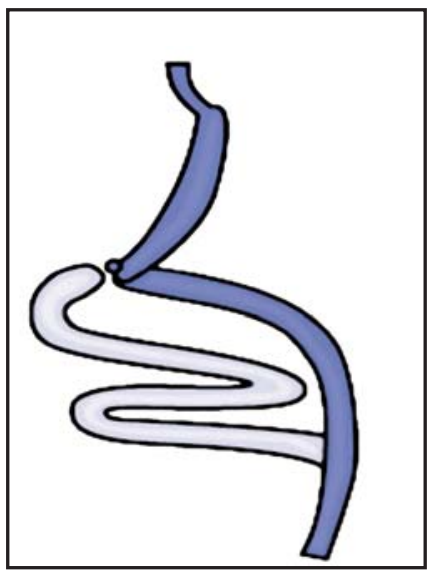

Fig. 3. Biliopancreatic Diversion with Duodenal Band Switch

or renal failure, inflammatory diseases of the gastro enteric tract, neoplastic diseases and inherited coagulation disorders $(7,8)$.

\section{EFFECT OF SURGERY}

The biliopancreatic derivation (DBP) shows best effectiveness, followed by the gastric encircling anastomosis (BPG), the vertical calibrated gastroplastica (GVC) and the gastric adjusting band (CGA). The weight loss depending on the applied technique is shown in Table 1.: 
Table 1.

\begin{tabular}{|l|c|c|c|c|}
\hline Method & $\begin{array}{c}\text { RouX-en-Y Gastric } \\
\text { Bypass }\end{array}$ & $\begin{array}{c}\text { Vertical Sleeve } \\
\text { Gastrectomy }\end{array}$ & $\begin{array}{c}\text { Adjustable } \\
\text { Gastric Band }\end{array}$ & $\begin{array}{c}\text { Biliopancreatic Bypass } \\
\text { With a Duodenal Switch }\end{array}$ \\
\hline Median weigh loss & $60-70 \%$ & $50-60 \%$ & $50-60 \%$ & $70-80 \%$ \\
\hline
\end{tabular}

\section{COMPLICATIONS}

Early complications of these operations can include bleeding, infection, leaks from the site where the intestines are sewn together, and blood clots in the legs that can progress to the lungs and heart. Examples of complications that may occur later include malnutrition, especially in patients who do not take their prescribed vitamins and minerals. In some cases, if the malnutrition is not addressed promptly, diseases such as pellagra, beri beri, and kwashiorkor may occur along with permanent damage to the nervous system. Other late complications include strictures (narrowing of the sites where the intestine is joined) and hernias $(9,10)$. Two kinds of hernias may occur after a patient has bariatric surgery. An incisional hernia is a weakness that sticks out from the abdominal wall's fascia (connective tissue) and may cause a blockage in the bowel. An internal hernia occurs when the small bowel is displaced into pockets in the lining of the abdomen. These pockets are created when the intestines are sewn together. Internal hernias are considered more dangerous than incisional ones and need prompt attention to avoid serious complications. Research indicates that about 10 percent of patients who undergo bariatric surgery may have unsatisfactory weight loss or regain much of the weight that they lost. Some behaviors such as frequent snacking on high-calorie foods or lack of exercise can contribute to inadequate weight loss. Technical problems that may occur with the operation, like a stretched pouch or separated stitches, may also contribute to inadequate weight loss. Some patients may also require emotional support to help them through the postoperative changes in body image and personal relationships. The bariatric surgery remains an aggressive treatment with risky complications and unpleasant sensations in the early period. In Roux-en-Y Gastric Bypass the intra operative mortality is around $0.5 \%$ in larger series and morbidity between $10 \%$ and $20 \%$, as the most common causes are anastomotic leaks due to a fistula, hemorrhage, intestinal occlusion and mechanical ileus, severe wound infections and less often thromboembolism despite the anticoagulant prophylaxis. In a longer period of time, the observed disorders are malabsorpion of metals, mostly iron and vitamins of B group (B12, B1), folic acid and calcium with a risk of secondary hiperparatiroidizam. Other complications are structure of the anastomosis $(5 \%)$, sore of the anastomosis (2-3\%), mechanical ileus and internal hernia (3-5\%).

Table 2.

\begin{tabular}{|l|c|c|c|c|}
\hline & $\begin{array}{c}\text { Roux-en-Y Gastric } \\
\text { Bypass }\end{array}$ & $\begin{array}{c}\text { Vertical Sleeve } \\
\text { Gastrectomy }\end{array}$ & $\begin{array}{c}\text { Adjustable } \\
\text { Gastric Band }\end{array}$ & $\begin{array}{c}\text { Biliopancreatic } \\
\text { Bypass With } \\
\text { a Duodenal Switch }\end{array}$ \\
\hline Mortality & $0.5 \%$ & $0.1 \%$ & $0.1 \%$ & $1.1 \%$ \\
\hline Morbidity & $10-20 \%$ & $5-20 \%$ & $<5 \%$ & \\
\hline Reoperation & $4 \%$ & $30 \%$ & $30 \%$ & \\
\hline
\end{tabular}

The mortality associated with the Vertical Sleeve Gastrectomy is less than $1 \%$ and the operative morbidity is approximately $5-20 \%$ according to the different authors Table 2.

In a long-term aspect the frequently occurring complications are: disintegration of the vertical agrafs, gastroesofagic reflux, and food intolerance accompanied by structure when meat is consumed, and decrease of the average iron and vitamin B12 values. These complications require operative correction.

Adjustable Gastric Band (CGA) is accompanied by a minimum percentage of intra operative mortality, almost $0 \%$ in most series. The value of early complications below $5 \%$, with minimal complications in the early postoperative period. Insufficiency in malabsorption of Vitamin B12 and Folic Acid may occur. The complications associated with the late postoperative period are slipping of the tightening band 2$12 \%$, reflux esofagitis and food intolerance up to $25 \%$, progressive dilatation of the stomach with pseudo achalaziya $5-60 \%$ and complications in the formation of gastric pouch to $10 \%(11,12)$.

Biliopancreatic Bypass with a Duodenal Switch (DBP) has $1.1 \%$ mortality and more severe complications in longterm aspect. Disorders related to iron absorption and formation of oxalate kidney stones are observed. 


\section{CONCLUSION}

Obesity surgery is the only method allowing aattainment of long-term weight reduction. The gastric encircling anastomosis is a method of choice with the desired late results. This intervention is carried out by a team of specialists after preoperative consultation with psychologist, anaesthesiologist and gastroenterologist. After the surgery, monitoring is of great importance. It has to be performed for a long period of time in order to correct the absorption disorders and food intolerance occurring after the operation. Monthly consultation with dietician and physical activity are recommended.

\section{REFERENCES:}

1. Cummings D.E., Weigle D.S., Frayo R.S. Plasma ghrelin levels after diet-induced weight loss or gastric bypass surgery. $\mathrm{N}$ Engl J Med 2002; 346:1623-30.

2. Rubino F., Gagner M., Gentileschi P. The early effect of the Roux-en-Y gastric bypass on hormones involved in body weight regulation and glucose metabolism. Ann Surg 2004;240:236-42

3. Biertho L., Steffen R., Ricklin T., et al. Laparoscopic gastric bypass versus laparoscopic adjustable gastric banding: A comparative study of 1200 cases. J Am Coll Surg 2003; 197:536-47.

4. Weber M., Mьller M.K., Bucher T., et al. Laparoscopic gastric bypass is superior to laparoscopic gastric banding for treatment of morbid obesity. Ann Surg
2004; 240:975-83.

5. Scopinaro N., Adami G.F., Marinari G., et al. Biliopancreatic diversion. World J Surg 1998;22:936-46.

6. Marceau P., Hould F.S., Simard S., et al. Biliopancreatic diversion with duodenal switch. World J Surg 1998; 22:947-54.

7. Consensus Development Conference Panel. Gastrointestinal surgery for severe obesity: Consensus development conference statement. Ann Intern Med 1991; 115:956-61.

8. Consensus sur le traitement de 1'obйsitй en Suisse. Schweiz Med Wochenschr 1999; 129:4S-20S.

9. Steffen R., Biertho L., Ricklin T., et al. Laparoscopic swedish adjustable gastric banding: A five-year prospective study. Obes Surg 2003; 13:404-11.

10. Martikainen T., Pirinen E., Alhava E., et al. Long-term results, late complications and quality of life in a series of adjustable gastric banding. Obesi Surg 2004; 14:648-54.

11. Msika S. La chirurgie de l'obйsitй morbide de l'adulte: 2. complications. Rйsultats de l'йvaluation technologique de 1'ANAES. J Chir 2003; 140. 20 **

12. Chapman A.E., Kiroff G., Game P., et al. Laparoscopic adjustable gastric banding in the treatment of obesity: A systematic literature review. Surgery 2004; 135:326-51.

\section{Corresponding author:}

Ludmil Marinov Veltchev, MD PhD

Mobile: +359876259685

E-mail: drlmarinov@yahoo.com 